\title{
Estudo epidemiológico da raiva bovina no Estado do Rio de Janeiro, Brasil (1980-1992)
}

\section{Epidemiological studies of rabies in cattle in the State of Rio de Janeiro, Brazil (1980-1992)}

\author{
Alcebíades da Silva Santos Feital ${ }^{1}$, Ulisses Eugenio Cavalcanti Confalonieri²
}

\section{Resumo}

Foi realizado um estudo sobre a ocorrência da raiva bovina no Estado do Rio de Janeiro durante o período de 1980 a 1992. Tomaram-se como base as notificações da doença no campo, anotadas pelo Serviço de Sanidade Animal do Ministério da Agricultura Abastecimento e Reforma Agrária, no Rio de Janeiro, bem como os diagnósticos registrados pelos cinco laboratórios especializados existentes no Estado. Verificou-se uma maior ocorrência de casos positivos nas regiões Metropolitana e SulFluminense, enquanto as regiões Noroeste e Baixadas Litorâneas e dos Lagos apresentaram os menores índices. As taxas de incidência variaram de zero a 187,3 por 1.000 .000 de animais e a variação anual da raiva teve maior expressão em todo o Estado nos anos de 1990 a 1992. Nesse período observou-se um aumento no número de municípios com rebanhos afetados, indicado pelas maiores taxas de incidência e pelo elevado percentual de diagnósticos suspeitos, confirmados, posteriormente, pelos laboratórios de diagnóstico.

Foram discutidas a variação no tempo e no espaço regional com base em fatores como a densidade do rebanho bovino, a freqüência da coleta de amostras para diagnóstico, as modificações ambientais decorrentes da construção de vias de transporte e o número de doses da vacina anti-rábica aplicadas.

Foram estimadas ainda as perdas econômicas diretas decorrentes da raiva bovina no Estado do Rio de Janeiro, no período estudado, chegando-se ao valor aproximado de US\$5.778,360.20, em virtude da redução da produção de leite e de carne. As perdas indiretas foram estimadas em torno de US\$ 8.667,540.30.

Palavras chave: raiva bovina; morcego hematófago; epidemiologia; Estado do Rio de Janeiro

\section{Introdução}

Embora a raiva, enquanto zoonose, no Brasil tenha declinado em incidência na última década no que concerne ao seu ciclo urbano/canino, em virtude da implantação, em 1973, no Ministério da Saúde, do Plano Nacional de Profilaxia da Raiva (Belloto, 1985), o mesmo não aconteceu com a raiva dos herbívoros, transmitida por quirópteros (Brasil, 1980). Fatores de natureza políticoadministrativa, socio-econômica e ecológica concorreram para isso e o aumento do número de agressões humanas por morcegos hematófagos, nos últimos anos, levou esses transmissores à segunda posição de veiculadores do vírus rábico para o homem, através de mordeduras, perdendo apenas para os cães (Brasil, 1992).

Dados do Ministério da Agricultura, Abastecimento e. Reforma Agrária para o ano de 1992 mostram que dos 715 casos de raiva bovina diagnosticados no país, 93 (13\%) foram no Rio de Janeiro (Brasil, 1992).

Neste trabalho objetivou-se descrever a ocorrência da raiva bovina no Estado do Rio de Janeiro, de 1980 a 1992, discutindo-se os fatores que influenciaram a ocorrência da doença nas diferentes regiões do Estado. Procurouse ainda verificar o impacto que a raiva trouxe às economias dos criadores e ao Estado ao longo desse período. Os dados encontrados podem subsidiar a elaboração de programas regionais de controle dessa enfermidade.

\section{Material e Métodos}

Fontes de dados - As informações sobre a raiva animal no período de 1980 a 1992 foram obtidas junto à representação do Ministério da Agricultura, Abastecimento e Reforma Agrária no Rio de Janeiro, ou seja, no Serviço de Sanidade Animal (SSA/RJ). Informações complementares foram também obtidas nos livros de protocolos dos laboratórios de diagnóstico de raiva existentes no Estado do Rio de Janeiro: Instituto Municipal de Medicina Veterinária Jorge Vaitsman, na cidade do Rio de Janeiro; Instituto Vital Brazil, em Niterói; Setor de Diagnóstico da Raiva da Universidade Federal Rural do Rio de Janeiro UFRRJ, em Itaguaí; Fundação para Desenvolvimento da Região Norte - Fundenor, em Campos dos Goytacazes e Empresa de Pesquisa Agropecuária do Estado do Rio de Janeiro - Pesagro-Rio, em Niterói.

\footnotetext{
${ }^{1}$ Serviço de Sanidade Animal, Ministério da Agricultura, Abastecimento e Reforma Agrária, Avenida Rodrigues Alves 129, $7^{\circ}$ andar, $20081-250$ Rio de Janeiro, RJ, Brasil

2 Escola Nacional de Saúde Pública, Fiocruz e Faculdade de Veterinária, Universidade Federal Fluminense, Rua Vital Brazil Filho 64, $24230-340$ Niterói, RJ, Brasil
} 
A unidade de análise utilizada no estudo foi o número de casos de raiva bovina confirmada por diagnóstico em laboratórios oficiais do Estado.

Taxa de incidência $=\frac{\begin{array}{c}\text { No de bovinos doentes/ } \\ \text { ano no estado } \\ \text { (região/município) }\end{array}}{\begin{array}{c}\text { Rebanho bovino do } \\ \text { estado (região/município) }\end{array}} \times T\left(\right.$ ano) $\times 10^{6}$

A taxa de coleta serviu para medir o número de amostras bovinas coletadas e enviadas para diagnóstico de raiva em função do rebanho de cada região do Estado.

№ de amostras enviadas a cada ano (região/município)

Taxa de coleta $=1$. Rebanho bovino (região/município)

A taxa de ocorrência da doença serviu para avaliar a área do Estado afetada pela raiva. Seu valor foi obtido pela seguinte fórmula:

№ de municípios com doença a cada ano Taxa de ocorrência $=\frac{}{\mathrm{N} N \text { o de municípios do estado }}$

Procurou-se classificar a autoria da coleta das amostras enviadas para os laboratórios segundo as três categorias: Profissional do Serviço de Defesa Sanitária; Médico Veterinário Autônomo e Proprietário/outros.

Cálculos dos prejuízos econômicos devido à raiva bovina - Calcularam-se os prejuízos econômicos a partir da multiplicação do número de casos de raiva bovina com diagnóstico laboratorial confirmado pelo coeficiente de 5,03 . Obteve-se esse coeficiente a partir dos dados lançados pelos técnicos do SSA nas "Ficha Epidemiológica de Raiva - $\mathrm{RA}_{2}$ " relatando o número de bovinos mortos em cada propriedade visitada com diagnóstico de raiva confirmado em laboratório. O coeficiente encontrado resultou do número de bovinos mortos suspeitos, dividido pelo número de bovinos mortos com diagnóstico de raiva, confirmado em laboratório, oriundos das propriedades visitadas pelos Médicos Veterinários do SSA e com apresentação de relatório em ficha própria.

Os prejuízos econômicos analisados foram os diretos e indiretos. Os prejuízos diretos foram calculados em função do peso da carcaça bovina e da produção leiteira dos animais mortos pela raiva. Para o cálculo desses valores consultou-se a literatura e verificou-se que o peso médio de carcaça dos bovinos abatidos no Brasil é de $215 \mathrm{~kg}$ (FAO, 1991). Este peso foi então considerado para avaliação dos prejuízos dos bovinos mortos pela raiva no Estado do Rio de Janeiro.
O cálculo dos prejuízos diretos devidos à perda leiteira baseou-se nos dados da Fundação IBGE, publicados em "Produção Pecuária Municipal" de 1980 a 1992, e resultou na produção média por vaca de 2,94 litros de leite/dia para o rebanho do Estado.

Com o cálculo do número de bovinos estimados como mortos pela raiva em 2.972 animais e, de acordo com as probabilidades estatísticas de $50 \%$ serem machos e outros $50 \%$ serem fêmeas, procederam-se aos cálculos das perdas leiteiras, também considerando que a vida média útil produtiva de uma vaca é de seis parições, e por conseqüência, seis lactações.

Os valores de mercado para a arroba do boi gordo (15 $\mathrm{kg}$ ) de US\$25.00 e para o litro de leite de vaca de US\$ 0.50 , foram obtidos pelo preço praticado no mercado, publicado em 15/03/94 (Jornal do Commercio, 1994) e convertido para o valor em moeda norte-americana pela cotação da mesma data.

O cálculo foi feito da seguinte forma:

A) Carcaças

№ de bovinos mortos $\times 215 \mathrm{~kg}=$ total em $\mathrm{kg}$ Total de peso das carcaças $\mathrm{kg}_{s} 15 \mathrm{~kg}=\mathrm{n}^{\circ}$ de arrobas Preço de arroba em US $\$ \times n=$ de arrobas = prejuízo em US\$

B) Leite

№ de vacas mortas $x$ média de litro de leite/vaca/ dia $x$ dias de lactação $x$ no médio anos de lactação $\times$ preço do litro de leite em US $\$=$ prejuízo em US\$

Os prejuízos indiretos, segundo Mitchell e Burns (1974), correspondem a $150 \%$ dos diretos.

A soma dos prejuízos diretos e indiretos é o total das perdas econômicas dos pecuaristas devido à raiva bovina. Os prejuízos do setor público ocorreram pelo não recolhimento do Imposto de Circulação de Mercadorias e Serviços (ICMS), tanto da carne como do leite, numa alíquota de $18 \%$, segundo dados da Secretaria de Fazenda do Estado do Rio de Janeiro, usando-se a seguinte fórmula:

Total dos prejuízos dos pecuaristas $\times 18 \%$ = prejuízo do Estado (em US\$).

\section{Resultados}

Entre 1980 e 1992, 114.382 exames laboratoriais para raiva foram realizados em todas as espécies animais, no Brasil. Desses, 15.373 foram realizados no Estado do Rio de Janeiro, sendo que 591 foram exames em bovinos positivos para raiva no Estado (Brasil, 1980-1992).

A região do Estado que concentrou o maior número de casos de raiva bovina no período foi a Metropolitana $(41 \%)$ e a com menor proporção de casos foi a da região dos Lagos e Baixadas Litorâneas com 1\% (Fig. 1). 


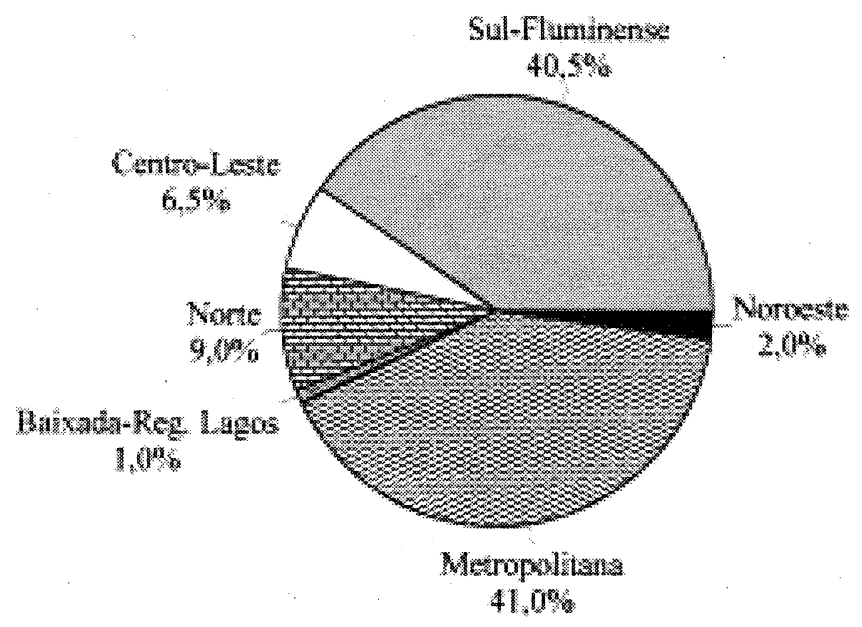

Figura 1 - Distribuição percentual da Raiva bovina por região do Estado do Rio de Janeiro (1980-1992).

Para uma melhor visualização comparativa das características regionais da taxa de coleta das amostras, das taxas de incidência, da densidade bovina e da distribuição percentual da raiva foram selecionados os anos de 1980, 1985, 1990, em que houve censo agropecuário, e 1992, o último ano desta pesquisa, para visualização em mapas (Figs. 2 a 5).

Uma plotagem da distribuição sazonal dos casos de raiva bovina nos 13 anos do estudo demonstrou uma ligeira tendência à predominância de casos no período de março a agosto, com pico de ocorrência neste último mês (Fig. 6).
A taxa de incidência $\left(\times 10^{6}\right)$ da raiva bovina no Estado (1980/1992), variou de 9,99 por 1.000 .000 (1982) a 47,90 por 1.000.000, em 1992 (Fig. 7). A regressão linear desta taxa mostrou uma tendência de crescimento da enfermidade no rebanho bovino da ordem de 2,51 casos por miIhão de animais/ano.

O maior número de exames de amostras de bovinos para pesquisa de raiva foi realizado pelo Laboratório do Instituto Jorge Vaitsman (33,5\%), seguido pelo Laboratório da UFRRJ (24,5\%), pelo da PESAGRO-Rio $(24,4 \%)$, pelo da FUNDENOR $(14,2 \%)$ e, finalmente, pelo do Instituto Vital Brasil (3,2\%).

Quanto ao perfil do coletor das amostras positivas de bovinos, verificou-se o predomínio em todos os anos dos profissionais do SSA, cuja participação variou de $89,2 \%$ das amostras coletadas no ano de 1981 a 46,9\% das coletadas em 1991. Os Médicos Veterinários autônomos responderam por percentuais de coleta que variaram de $4,1 \%$ das amostras (1983) a 30,1\% (1992), enquanto a categoria "Proprietário/outros" respondeu por participações que variaram de 3,7\% (1988) a 37,1\% (1991).

O número de propriedades nas quais foram obtidas amostras positivas variou de 18 em 1982 a 91 em 1992.

Levando-se em consideração a variação no número de municípios no Estado do Rio de Janeiro, de 1980 a 1992, obteve-se a variação do percentual de municípios afetados pela raiva no período, notando-se uma tendência crescente. Na Fig. 7 visualizam-se as tendências nas taxas de incidência, no percentual de amostras positivas,

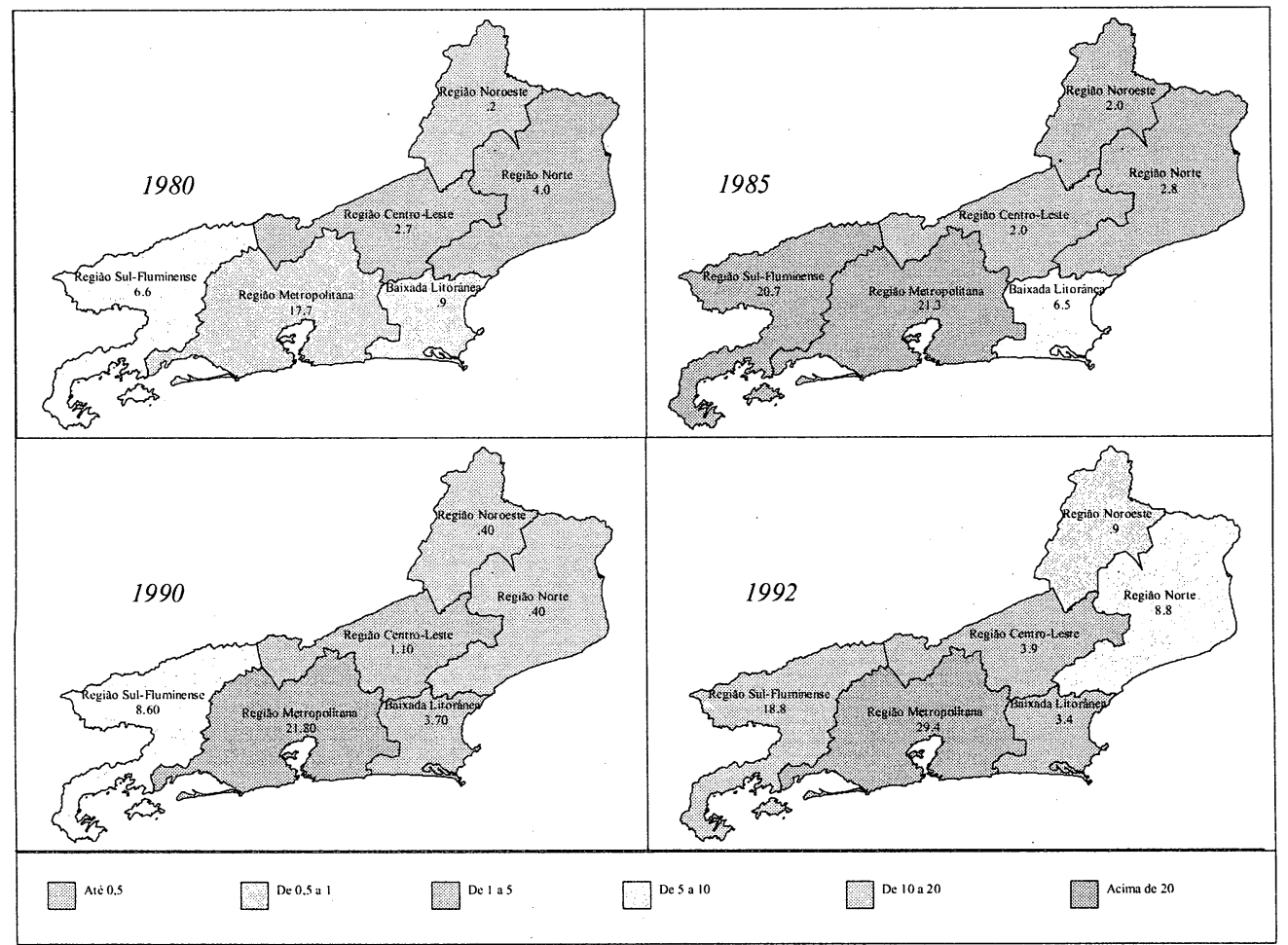

Figura 2 - Taxa de Coleta de Amostras $\left(\times 10^{6}\right)$ para diagnóstico de Raiva bovina, segundo as regiões do Estado do Rio de Janeiro, nos anos de 1980, 1985, 1990 e 1992. 


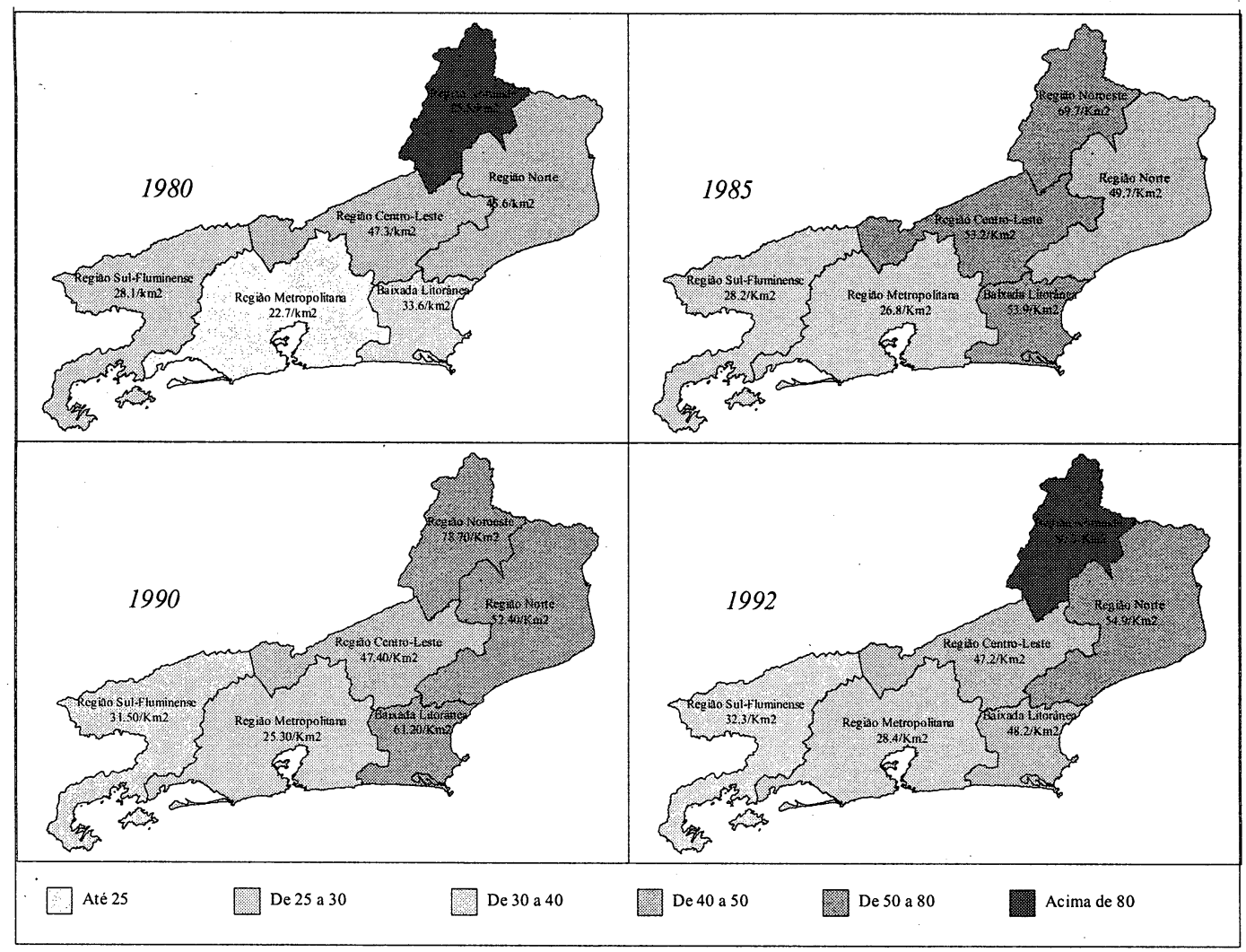

Figura 3 - Densidade bovina por Km², segundo as regiões do Estado do Rio de Janeiro, nos anos de 1980, 1985,1990 e 1992.

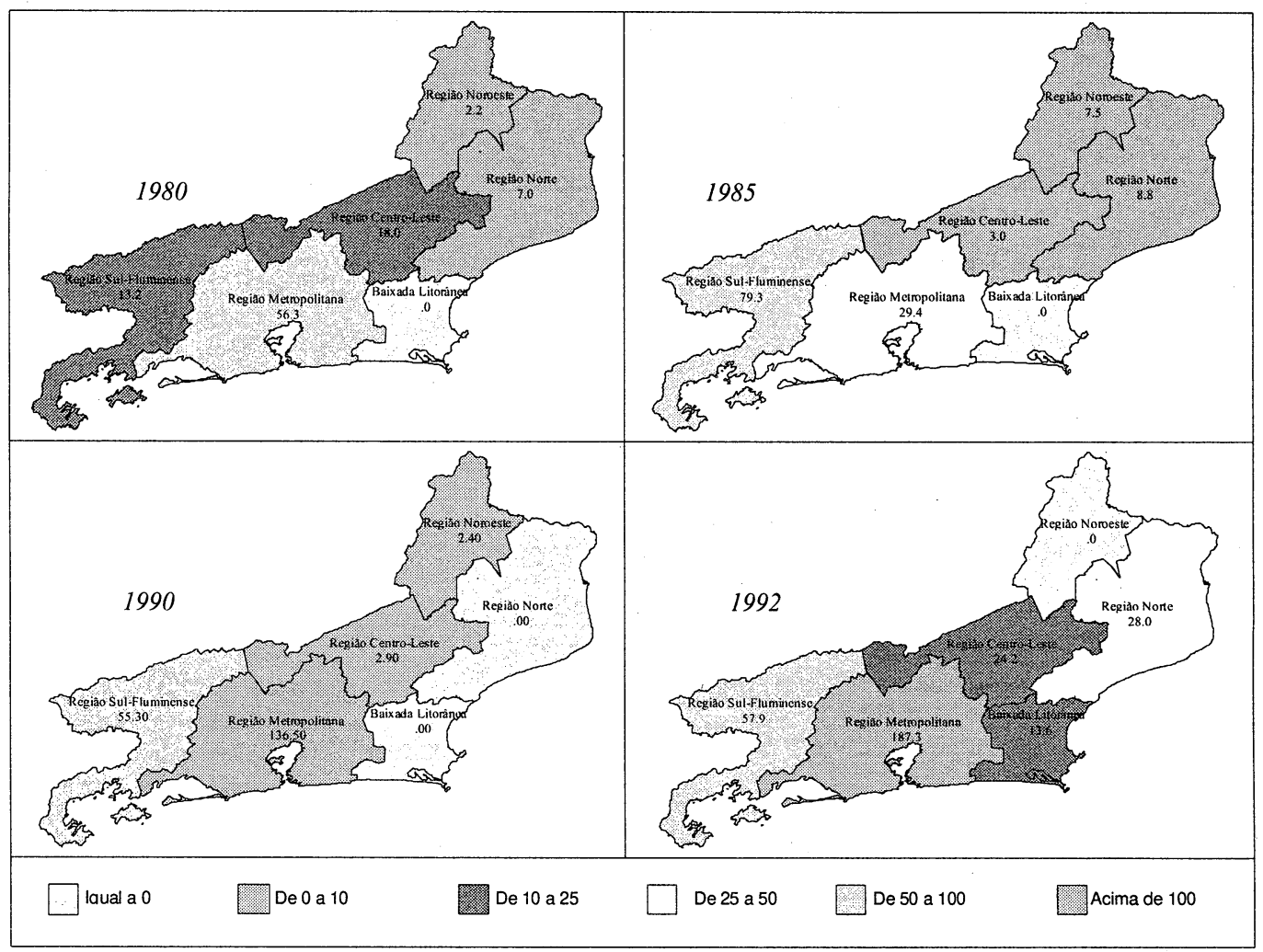

Figura 4 - Taxa de incidência da Raiva bovina (x106), segundo as regiões do Estado do Rio de Janeiro, nos anos de $1980,1985,1990$ e 1992. 


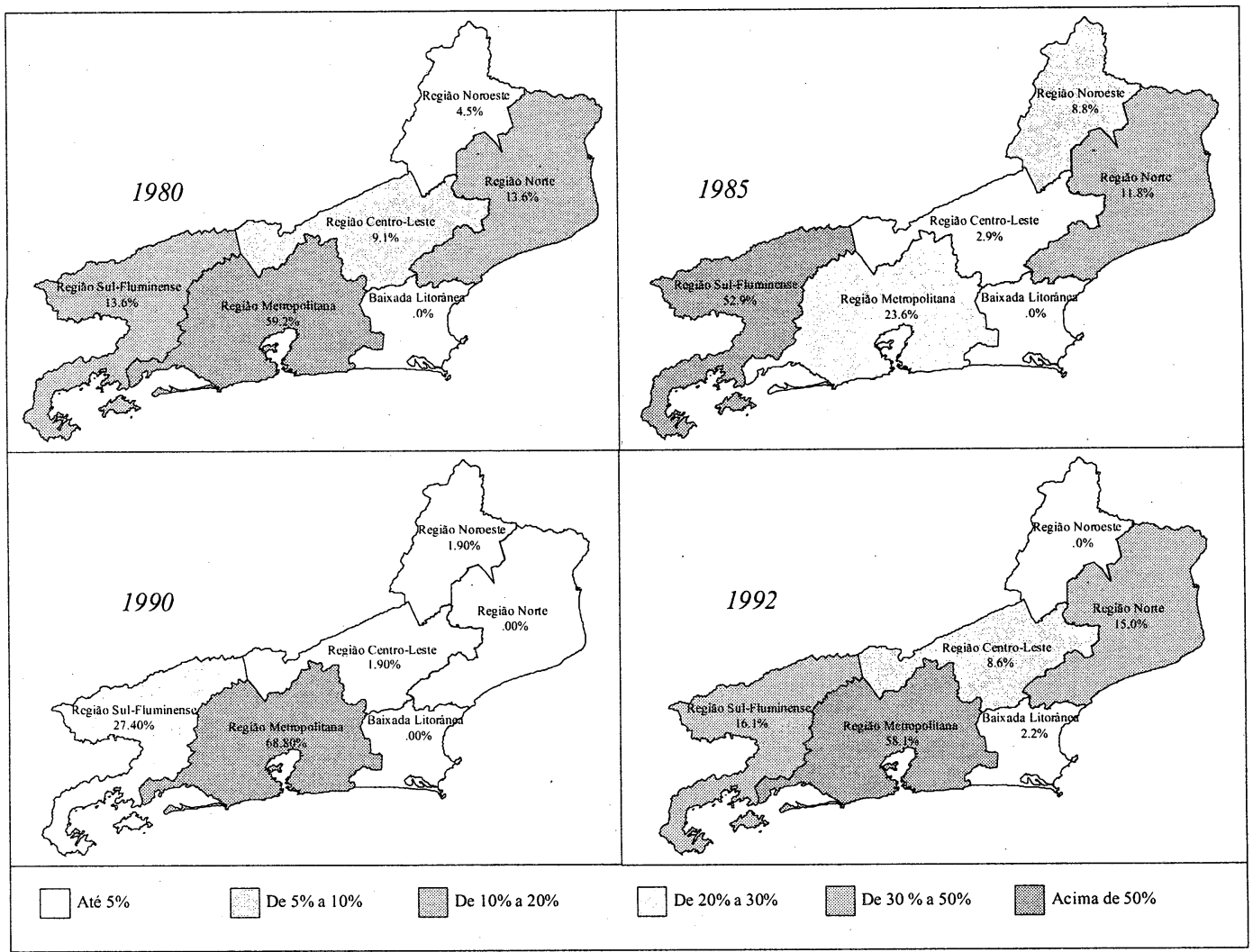

Figura 5: Distribuição percentual de casos de Raiva bovina, segundo as regiões do Estado do Rio de Janeiro, nos anos de 1980, 1985,1990 e 1992.

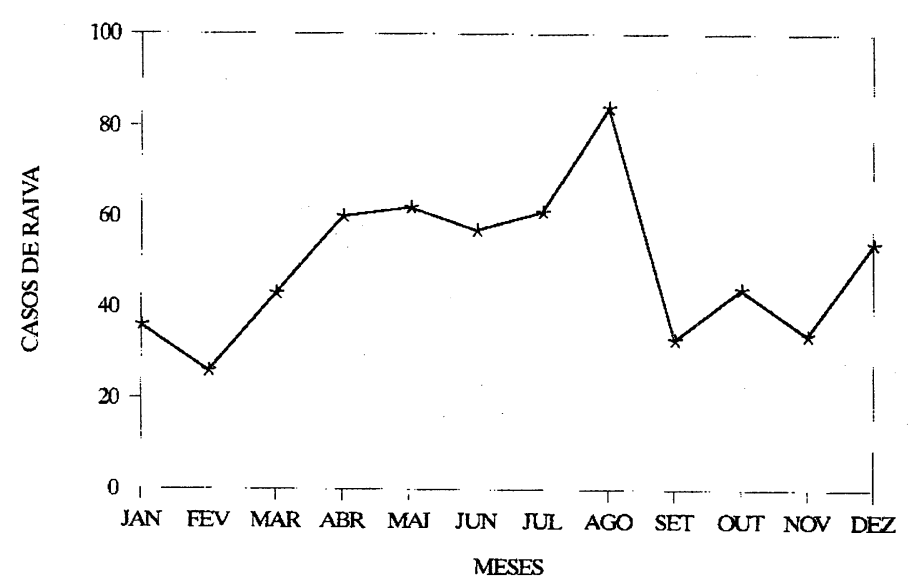

Figura 6: Variação mensal agrupada da raiva bovina no Estado do Rio de Janeiro (1980-1992).

no número absoluto de casos de raiva bovina, bem como na proporção de municípios com bovinos afetados pela doença em cada ano do período estudado.

Tendo em vista a importância da vacinação anti-rábica dos animais suscetíveis na prevenção da doença, os dados percentuais de cobertura vacinal no período foram computados, notando-se o maior percentual no ano de 1985 (5,8\% do rebanho do Estado) tendo a cobertura dos demais anos variado entre 1,9\% (1980) e 4,4\% (1981).

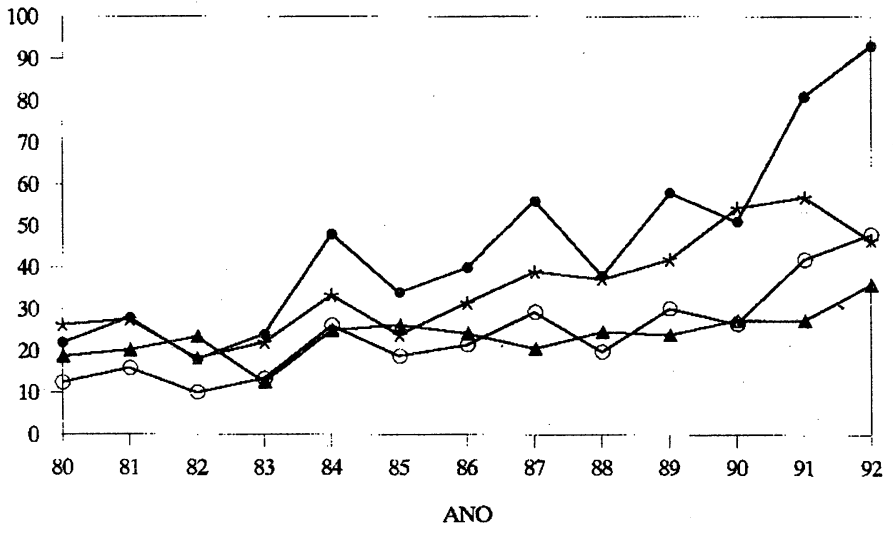

*\% Positividade - № casos $\star \%$ Municipios afetados $\Theta$ Taxa Incidência (x10 6 )

Figura 7: Gráfico comparativo da variação da ocorrência de raiva bovina no Estado do Rio de Janeiro (1980-1992).

A análise dos principais indicadores da raiva bovina no Rio de Janeiro de 1980 a 1992 (número absoluto de casos, percentual de positividade das amostras, percentual de municípios afetados e taxa de incidência) mostrou uma nítida tendência crescente no período (Fig. 7).

Com relação às perdas econômicas para os produtores, causadas pela doença, os seguintes valores estimados foram obtidos: 
Perdas diretas - Produção leiteira: perda de cerca de US\$4.718,347.20 correspondentes a 9.436 .694 litros não produzidos. Produção de carne: perda de US\$1.060, 013.00, correspondentes a 42.400 arrobas não produzidas.

Perdas indiretas - Equivalentes a $150 \%$ do total das perdas diretas, num total de US\$ $8.667,540.30$, correspondentes à expoliação sangüínea, perda de peso, depreciação do couro, bezerros não produzidos, etc.

Para o poder público, a perda estimada foi de cerca de US\$2.600,262.09 referentes ao imposto não recolhido devido à perda na produção, o que perfaz um total aproximado de US $\$ 17.046,162.59$ de prejuízos, quando somado às perdas dos criadores.

\section{Discussão}

A inversão da tendência na análise de amostras para raiva no Estado, segundo a espécie animal, observada a partir de 1986, quando passaram a predominar as de origem bovina, pode ser interpretada como resultando das ações de controle das populações de morcegos hematófagos, realizados pelos técnicos do SSA/RJ, do Ministério daAgricultura, Abastecimento e ReformaAgrária. Por outro lado, o declínio correspondente na remessa de amostras de outras origens, principalmente canina, foi reflexo das bem sucedidas campanhas anuais de vacinação anti-rábica em nível nacional, desenvolvidas pelo Programa Nacional de Profilaxia da Raiva, do Ministério da Saúde. Os cinco laboratórios de diagnóstico de raiva no Estado do Rio de Janeiro processaram, ao longo dos 13 anos estudados, 1.636 amostras bovinas de 1.597 propriedades rurais e o fato da região Metropolitana ter tido o maior percentual de remessa de amostras para exames, seguido pela região Sul-Fluminense, deveu-se à grande concentração de Médicos Veterinários na região, bem como à localização da maioria dos Laboratórios de Diagnóstico nessas áreas.

A análise da variação anual da ocorrência da raiva nos diferentes meses do ano (Fig. 6), demonstrou um aumento a partir dos meses do outono, atingindo o auge do número de casos positivos no inverno, resultados semeIhantes aos encontrados por Luz (1988), em Minas Gerais. Nesse período (abril a agosto) ocorreram os cinco maiores percentuais em relação ao número total de casos, fenômeno esse que pode estar relacionado a um possível aumento do número de movimentos migratórios dos morcegos, normalmente reduzido no período de maior precipitação de chuvas (primavera/verão).

Quanto à variação anual da raiva no período compreendido por este estudo (1980/1992) notou-se uma tendência para o aumento do número de casos nos últimos anos. Isso pode ser verificado tanto pelo número absoluto de casos laboratorialmente confirmados, quanto pelo crescente percentual de amostras positivas dentre aquelas remetidas para exame e ainda pelo aumento progressivo do percentual de municípios que tiveram bovinos afeta- dos pela doença, além da crescente taxa global de incidência no Estado. No que diz respeito a essa última, ao ser comparada por regiões, nos anos de 1980, 1985, 1990 e 1992 (Fig. 4) verificou-se que as regiões Metropolitana e Sul-Fluminense foram as que apresentaram os maiores índices, variando de 13,2 a 187,3/1.000.000 de bovinos. Todavia as demais regiões, nos mesmos anos, apresentaram taxas iguais a zero ou um pouco acima, mas sempre inferior a um, com exceção do ano de 1992, quando aparentemente houve aumento da incidência no Estado como um todo, a exceção da região Noroeste. Nesse ano (e no de 1991) observaram-se os maiores valores de todos os indicadores de ocorrência de raiva no Estado, não só a taxa de incidência mas também o número absoluto de casos, o percentual de amostras positivas enviadas para exames e também o percentual de municípios do Estado com casos da infecção (Fig. 7).

No único estudo similar (Luz, 1988) realizado em Minas Gerais, foram observadas taxas de incidência de raiva bovina variando de 0,29/1.000.000 (ano de 1969) a $8,35 / 1.000 .000$ (em 1986). Tomando-se essas taxas de incidência, junto com a distribuição percentual dos casos nas regiões nos quatro anos selecionados neste estudo, observou-se uma variação inversa àquela relativa à densidade do rebanho bovino: as regiões Metropolitana e SulFluminense, mais afetadas pela zoonose, foram as que apresentaram o menor número médio de animais por $\mathrm{km}^{2}$ de território. Por outro lado, mostrou-se uma relação direta importante entre a ocorrência da raiva e a intensidade das ações de vigilância epidemiológica, representadas tanto pelo número de propriedades com assistência veterinária permanente (granjas leiteras tipo $A / B$ ) como pela taxa de coleta de amostras para confirmação laboratorial da doença.

Em relação aos possíveis conjuntos de fatores envolvidos na variação da ocorrência da raiva bovina, duas grandes categorias devem ser assinaladas: uma relativa aos fatores naturais ou seja, aqueles relativos ao meio ambiente ligados aos transmissores e à circulação de vírus entre suas colônias e a outra relativa às ações empreendidas pela sociedade para controlar essa zoonose, principalmente a vacinação e o controle de morcegos. Quanto a esta última acredita-se que o fator determinante do aumento da raiva bovina no Estado do Rio de Janeiro, de 1980 a 1992, foi a redução nas ações de Defesa Sanitária Animal por parte do Ministério daAgricultura e do Abastecimento, observada mais nitidamente a partir do ano de 1986. Observando-se os dados relativos ao perfil dos coletores das amostras positivas nota-se que houve um decréscimo progressivo na participação dos Médicos Veterinários dos Serviços Oficiais (SSA/MAA/RJ) na remessa de amostras para diagnóstico laboratorial. De uma participação acima de $80 \%$ do total de coletas, no período de 1980 a 1984, esses passaram a contribuir com apenas $46,9 \%$ das coletas em 1991 e $50,5 \%$ do total em 1992. A 
interferência de problemas político-administrativos tornou irregular a atuação de combate à raiva devido à colocação em disponibilidade e demissão de 25 desses profissionais em junho de 1990. Não por acaso os anos de 1990 e 1992 registraram a mais baixa taxa de cobertura de vacinação anti-rábica dos herbívoros no período estudado, excetuando-se o ano de 1980.

Por outro lado, no que tange aos fatores ambientais, verifica-se que muitos deles não são naturais já que resultaram da intervenção humana, com a modificação de ecosistemas em função de atividades econômicas. No caso da raiva dos herbívoros são importantes aquelas ações que envolvem alterações ambientais que facilitam a proliferação e dispersão de morcegos hematófagos, como a criação de nichos artificiais que lhes servem de abrigo. Nesse aspecto um registro especial deve ser feito para a região Sul-Fluminense que respondeu por $40,4 \%$ do total de casos no período estudado. A abertura de pelo menos $21 \mathrm{~km}$ de túneis da Ferrovia do Aço, entre os anos de 1979 a 1982, ficando a mesma um longo período sem utilização (1982/1987) foi um fenômeno relevante para a ocorrência da raiva já que esses locais passaram a albergar grandes populações de quirópteros, inclusive os hematófagos, conforme observações de campo. Esses focos de proliferação dos transmissores do vírus tiveram como áreas de influência prováveis os municípios de Volta Redonda e Barra Mansa e, provavelmente, em conseqüência disso, este último foi o terceiro município mais freqüente em número de casos de raiva bovina no Estado, de 1980 a 1992.

Analisada do ponto de vista econômico, a raiva bovina nos 13 anos de estudo causou aos pecuaristas e aos cofres públicos do Estado do Rio de Janeiro, prejuízos estimados em 17 milhões de dólares, fato que, aliado ao perigo da infecção humana, justifica medidas mais efetivas de controle dessa enfermidade no Estado como um todo, tendo-se, entretanto, o cuidado de se privilegiar as regiões com maiores taxas de incidência (Metropolitana e SulFluminense). Dentre estas deve-se dar atenção de imediato àqueles municípios de elevado teor de enzooticidade como, por exemplo, os que apresentaram casos em pelo menos três anos consecutivos.

\section{Abstract \\ Epidemiological studies of rabies in cattle in the State of Rio de Janeiro, Brazil (1980-1992)}

A study was performed on the occurrence of bovine rabies in the State of Rio de Janeiro. It was considered the period between 1980 and 1992. It started with the compilation of the occurrence of the disease in the rural areas made by the Animal Health Service of the Agriculture Ministry as well as with the diagnoses made by the five official laboratories in the State. A greater number of positive cases were found in the Metropolitana and Sul-Fluminense regions than in the Noroeste and Baixadas Litorâneas and Lagos regions. The incidence rates ranged from 0 to 187,3 for 1,000.000 animals and the annual rabies variation had a great expression in the whole State in the period from 1990 to 1992 . During this period it was observed an increase in the number of counties with affected herds showed by the elevated incidence rates and by the high percentage of suspected animals confirmed as positives by the laboratories.

It was also discussed the temporal and spatial variations based in facts such as the bovine population density; the frequency of samples collected for laboratory diagnoses; the environmental modifications due to railroad constructions; and the number of rabies vaccines applied.

It was estimated the direct economic losses due to the bovine babies in the State of Rio de Janeiro during the period studied, reaching US $\$ 5.778,360.20$ as a reduction in milk and meat production. The indirect losses were estimated to be around US $\$ 17.667,540.30$.

Key words: bovine rabies; epidemiology; vampire bat; State of Rio de Janeiro

\section{Referências bibliográficas}

BellotoAJ 1985. A raiva no Brasil em 1984. Aspectos operacionais e epidemiológicos. Rev Fund SESP 30(2): 167-182.

Brasil 1980. Ministério da Agricultura, Secretaria Nacional de Defesa Agropecuária-SNAD. Raiva dos Herbívoros. Bol Def Sanit Anim 14(1-4): 63-66.

Brasil 1992. Ministério da Agricultura, Abastecimento e Reforma Agrária, Secretaria Nacional de Defesa AgropecuáriaSNAD. Raiva Animal. Dados computados e não publicados referentes aos anos de 1990, 1991 e 1992, Brasília.

FAO - Food and Agricultural Organization 1991. Statistics Series 104, Production 45: 191-200.

Jornal do Commercio 1994. Indicadores: Mercado Agropecuário, Boi. Rio de Janeiro, 15 março.

Luz CR da 1988. Estudo cronológico sobre a raiva em Minas Gerais no período de 1976 a 1986. Dissertação de Mestrado, Universidade Federal de Minas Gerais, Belo Horizonte, 122 pp.

Mitchell GC, Burns RJ 1974. Combate Químico de los Murcielagos Vampiros. Centro Regional de Ajuda Técnica da AID, Mexico, Buenos Aires, 11 pp. 